\title{
Metabolic profile during pregnancy in BRISA birth cohorts of Ribeirão Preto and São Luís, Brazil
}

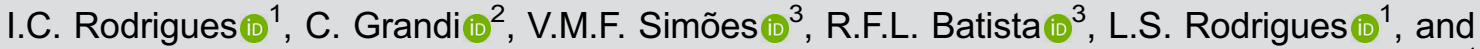 \\ V.C. Cardoso ii ${ }^{1}$ \\ ${ }^{1}$ Departamento de Puericultura e Pediatria, Faculdade de Medicina de Ribeirão Preto, Universidade de São Paulo, \\ Ribeirão Preto, SP, Brasil \\ ${ }^{2}$ Argentine Society of Pediatrics, Buenos Aires, Argentina \\ ${ }^{3}$ Departamento de Saúde Pública, Universidade Federal do Maranhão, São Luis, MA, Brasil
}

\begin{abstract}
During pregnancy, metabolic changes that develop in women may increase the risk of diseases and conditions that may also harm the life of the growing fetus. The aim of the present study was to identify and compare the metabolic profile (MP) during pregnancy in two birth cohorts in 2010 in the cities of Ribeirão Preto (RP) and São Luís (SL), Brazil. Pregnant women (1393 in $\mathrm{RP}$ and 1413 in SL) were studied; information was obtained through questionnaires in addition to anthropometric, biochemical, and blood pressure measurements. Data are presented as means and proportions. To compare the characteristics of pregnant women in both cities, chi-squared and Student's t-tests were applied, with $5 \%$ significance level. Ribeirão Preto presented higher mean values than SL for pre-gestational body mass index (24.5 vs $\left.23 \mathrm{~kg} / \mathrm{m}^{2}, \mathrm{P}<0.001\right)$, systolic $(108.4 \mathrm{vs} 102.8 \mathrm{mmHg}$, $\mathrm{P}<0.001)$ and diastolic $(65.9$ vs $61.8 \mathrm{mmHg}, \mathrm{P}<0.001)$ blood pressure, total cholesterol (226.3 vs $213.7 \mathrm{mg} / \mathrm{dL}, \mathrm{P}<0.001)$ and fractions, and glycemia ( $84.5 \mathrm{vs} 80.2 \mathrm{mg} / \mathrm{dL}, \mathrm{P}<0.001)$, except for triglycerides $(P=0.135)$. Women from RP also showed higher rates of pre-gestational overweight and obesity compared with SL (40.1 vs $25.8 \%)$. In the present study, pregnant women in RP had a worse gestational metabolic profile than those in SL, with higher pre-gestational excess weight, indicating that nutritional transition was more advanced in the more developed city.
\end{abstract}

Key words: Pregnancy; Cohort studies; Hypertension; Diabetes mellitus; Dyslipidemia

\section{Introduction}

Brazil and several other Latin American countries have been experiencing a rapid demographic, epidemiological, and nutritional transition in the last twenty years (1). The marked increase in the prevalence of obesity in various population subgroups, including pregnant women, is noteworthy (1).

Pregnancy induces remarkable changes in maternal metabolism to support fetal demands $(2,3)$. However, in some women the changes may be harmful and associated with adverse pregnancy outcomes; for example, gestational diabetes, hypertensive disorders, and preterm birth (3-5).

During pregnancy, high concentrations of total cholesterol, triglycerides, low-density lipoprotein cholesterol (LDL-C), and high-density lipoprotein cholesterol (HDL-C) are common (6). Serum lipid levels begin to increase from the 9th to the 13th week of gestation and peak at the 31st to 36th week (7). In addition, it's important to evaluate these levels during pregnancy, since lipid profile disorders are recognized to be involved in the pathophysiology of cardiovascular disease and diabetes (8-11).
Therefore, the identification of metabolic and inflammatory changes in pregnancy that may announce the risk of adverse outcomes is paramount. However, most epidemiological studies on the metabolic effects of pregnancy have a very small sample size and lack the possibility of replication (12). In addition, few studies addressed this issue in Brazilian pregnant women.

Thus, considering the scarcity in Brazilian literature and the relevance to maternal and child health, this study aimed to identify and compare the metabolic profile during pregnancy in two birth cohorts in the cities of Ribeirão Preto (RP) and São Luís (SL), Brazil.

\section{Material and Methods}

\section{Study design}

Secondary cross-sectional data obtained from two prenatal cohort studies, with a descriptive and analytical approach, was analyzed. 


\section{Study population}

This study was part of the "Etiological Factors of Preterm Birth and Consequences of Perinatal Factors in Child Health: Birth Cohorts in Two Brazilian Cities", known as BRISA (Brazilian Ribeirão Preto and São Luis Birth Cohort) study. The main objective of BRISA was to evaluate new risk factors for preterm birth (neuroendocrine, immunoinflammatory, and medical intervention hypotheses), perinatal health indicators, and the impact on growth in two cohorts in the cities of RP and SL (13).

During 2010, pregnant women were recruited at public and private prenatal health facilities at less than the $20^{+0}$ week gestational age (GA). Inclusion criteria were women residing in RP and SL, with a single pregnancy and $G A$ between $22^{+0}-25^{+6}$ weeks (13). At this time, 1400 pregnant women in RP and 1447 in SL were evaluated. After excluding women without a biochemical test, the final sample consisted of 2806 pregnant women (1393 in RP and 1413 in SL) in the prenatal evaluation (Figure 1).

\section{Prenatal evaluation}

Standardized questionnaires applied at $22^{+0}$ to $25^{+6}$ weeks GA included identification data, information on reproductive health, characteristics of the current pregnancy, age, education level, skin color, and marital status. Socioeconomic level categorized as A1/A2, B1, B2, C1/C2, and $D / E$, according to Brazilian Association of Research Companies (ABEP) (14) A1/A2 being the highest, prenatal visits, hypertension, diabetes, alcoholic and soft drink consumption, smoking, Block score (high-fat diet) (15), and type of delivery (vaginal, cesarean) were also evaluated.

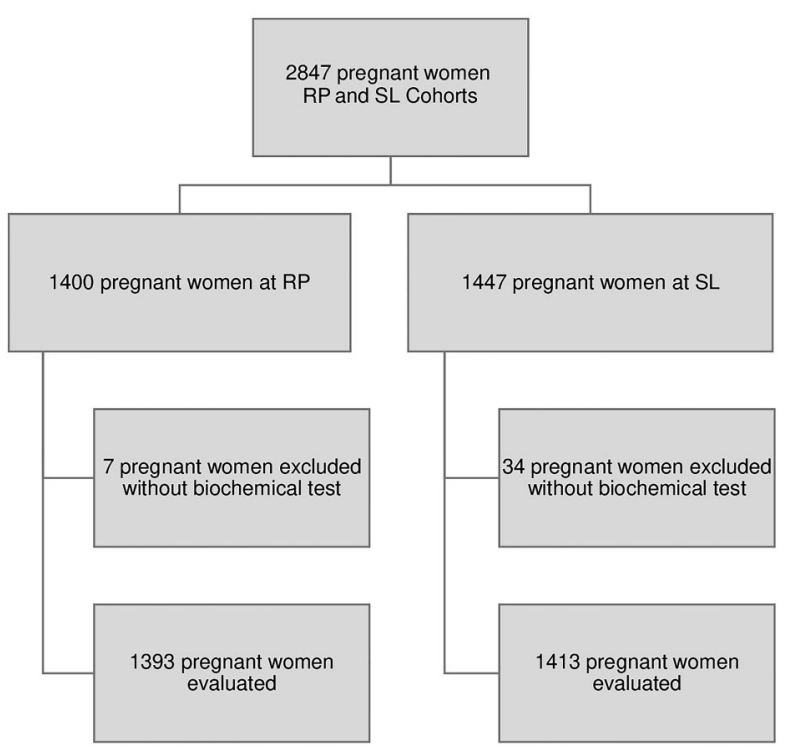

Figure 1. Flowchart of the study population. RP: Ribeirão Preto; SL: São Luis.
The short version of the International Physical Activity Questionnaire (IPAQ) was used to determine the physical activity level of the pregnant women, classified as vigorous or heavy, moderate, and light (16).

Non-fasting blood glucose and total cholesterol levels were measured using an enzymatic $A A$ technique, HDL-C by single-phase $A A$ plus colorimetric method, and triglycerides by GPO/PAP AA enzymatic method, all performed by the Wiener Lab CT600i autoanalyzer (Labinbraz Comercial LTDA, Brazil) at Ribeirão Preto Medical School, University of São Paulo laboratory. Blood pressure was measured two times using Omron 749 digital sphygmomanometer (OMRON Healthcare, Brazil) with a 15 min interval between measurements.

The maternal anthropometric measures were: selfreported pre-gestational weight $(\mathrm{kg})$, and gestational weight $(\mathrm{kg})$ and height $(\mathrm{cm})$ measured in the prenatal evaluation $\left(22^{+0}-25^{+6}\right.$ weeks) according to standardized techniques. Pre-gestational and gestational body mass index (BMI, $\mathrm{kg} / \mathrm{m}^{2}$ ) were calculated according to the WHO classification (17).

The metabolic profile was classified according to the criteria proposed by Chatzi et al. (18) for metabolic syndrome including the following risk factors: BMI $>30 \mathrm{~kg} / \mathrm{m}^{2}$, fasting blood glycemia $\geqslant 100 \mathrm{mg} / \mathrm{dL}$, systolic blood pressure $\geqslant 130$ and/or diastolic blood pressure $\geqslant 85$ $\mathrm{mmHg}$, triglycerides $\geqslant 150 \mathrm{mg} / \mathrm{dL}$, and $\mathrm{HDL}-\mathrm{C}<50 \mathrm{mg} / \mathrm{dL}$. Other biochemical markers evaluated were total cholesterol $\geqslant 250 \mathrm{mg} / \mathrm{dL}$ and LDL-C $\geqslant 130 \mathrm{mg} / \mathrm{dL}$.

\section{Statistical analysis}

Data are reported as means $\pm S D$ or proportions, whichever was appropriate. Statistical tests included Student's $t$-test and chi-squared test. A P value $<0.05$ was considered significant. All statistical analyses were performed using the statistical package Stata, version 13.0 (Stata Corp. LP, USA).

\section{Ethical aspects}

The databases were linked anonymously using encrypted individual health card numbers. The study was approved by the Research Ethics Committee of the Hospital das Clínicas and the Ribeirão Preto Medical School of the University of São Paulo (process number 11157/2008) and the Research Ethics Committee of the University Hospital of the Federal University of Maranhão (process number 4771/2008-30), and all participants freely signed the informed consent form.

Finally, we followed the STROBE (Statement for Reporting Observational Studies in Epidemiology) guidelines (19).

\section{Results}

There were significant socioeconomic differences between the cities. Ribeirão Preto presented higher 
adolescent (14.0 vs $10.4 \%$ ) and older pregnant women (10.1 vs $7.7 \%)$ rates, and lower level of schooling $(27.5$ vs $12.4 \%$ ) than SL. On the other hand, non-white women were almost double in SL (83.8\%) than RP $(48.5 \%)$, but RP presented a higher percentage of women from the higher economic classes A1/A2 (1.5 vs $0.5 \%$ ) (Table 1).

Compared with SL, Ribeirão Preto pregnant women had a higher intake of alcoholic drinks (25.1 vs $13.1 \%)$ and soft drinks (79.3 vs $57.9 \%)$ during pregnancy, were more sedentary (17.5 vs $6.6 \%$ ), and smoking rates were almost five times greater (12.7 vs $2.7 \%$ ). Altered Block scores showed no significant differences (Table 1).

RP showed significantly higher rates of pre-gestational overweight/obesity (40.1 vs $25.8 \%$ ), more prenatal visits (94.8 vs $82.9 \%$ ), and gestational diabetes (5.3 vs $2.7 \%$ ), but lower rates of gestational hypertension (14 vs $16.9 \%)$ and cesarean section (40.4 vs $50.2 \%$ ) than SL (Table 2).

All the anthropometric and blood pressure values were significantly higher in RP compared with SL pregnant women $(P<0.001)$ (Table 3).

Table 1. Maternal sociodemographic characteristics and life styles during pregnancy. Comparison between the Ribeirão Preto and São Luís 2010 cohorts.

\begin{tabular}{|c|c|c|c|}
\hline Characteristics & Ribeirão Preto (n, \%) & São Luís (n, \%) & $\mathrm{P}$ \\
\hline \multicolumn{4}{|l|}{ Sociodemographic } \\
\hline Age (years) & & & $<0.001$ \\
\hline $20-34$ & $1040(75.9 \%)$ & $1132(81.9 \%)$ & \\
\hline$<20$ & $192(14.0 \%)$ & $144(10.4 \%)$ & \\
\hline$\geqslant 35$ & $138(10.1 \%)$ & $106(7.7 \%)$ & \\
\hline Skin color & & & $<0.001$ \\
\hline White & $700(51.5 \%)$ & $224(16.2 \%)$ & \\
\hline Non-white & $658(48.5 \%)$ & $1157(83.8 \%)$ & \\
\hline Maternal education (years) & & & $<0.001$ \\
\hline$\geqslant 12$ & $114(8.4 \%)$ & $172(11.9 \%)$ & \\
\hline $9-11$ & $874(64.1 \%)$ & $1091(75.7 \%)$ & \\
\hline$\leqslant 8$ & $375(27.5 \%)$ & $179(12.4 \%)$ & \\
\hline Marital status (partner) & & & 0.360 \\
\hline Yes & $1138(81.5 \%)$ & $1160(80.2 \%)$ & \\
\hline No & $258(18.5 \%)$ & $287(19.8 \%)$ & \\
\hline Socioeconomic level (ABEP) & & & $<0.001$ \\
\hline $\mathrm{A} 1 / \mathrm{A} 2$ & $20(1.5 \%)$ & $7(0.5 \%)$ & \\
\hline B1 & $55(4.2 \%)$ & $38(2.7 \%)$ & \\
\hline B2 & $293(22.3 \%)$ & $176(12.7 \%)$ & \\
\hline $\mathrm{C} 1 / \mathrm{C} 2$ & $794(60.3 \%)$ & $933(67.6 \%)$ & \\
\hline $\mathrm{D} / \mathrm{E}$ & $154(11.7 \%)$ & $226(16.3 \%)$ & \\
\hline \multicolumn{4}{|l|}{ Life style during pregnancy } \\
\hline Alcoholic drink consumption & & & $<0.001$ \\
\hline Yes & $344(25.1 \%)$ & $181(13.1 \%)$ & \\
\hline No & $1026(74.9 \%)$ & $1021(86.9 \%)$ & \\
\hline Soft drinks consumption & & & $<0.001$ \\
\hline Yes & $1107(79.3 \%)$ & $837(57.9 \%)$ & \\
\hline No & $288(20.7)$ & $609(42.1 \%)$ & \\
\hline Smoking & & & $<0.001$ \\
\hline Yes & $174(12.7 \%)$ & $38(2.7 \%)$ & \\
\hline No & $1196(87.3 \%)$ & $1344(97.3 \%)$ & \\
\hline Block score altered $(>27)$ & & & 0.600 \\
\hline Yes & $396(28.4 \%)$ & $398(27.5 \%)$ & \\
\hline No & $998(71.6 \%)$ & $1048(72.5 \%)$ & \\
\hline Physical activity & & & $<0.001$ \\
\hline Sedentary & $244(17.5 \%)$ & $95(6.6 \%)$ & \\
\hline Light & $455(32.7 \%)$ & $487(33.6 \%)$ & \\
\hline Moderate & $404(29.1 \%)$ & $601(41.5 \%)$ & \\
\hline High & $288(20.7 \%)$ & $264(18.3 \%)$ & \\
\hline
\end{tabular}

Chi-squared test was used. ABEP: Association of Research Companies. 
Table 2. Reproductive and obstetric characteristics. Comparison between the Ribeirão Preto and São Luís 2010 birth cohorts.

\begin{tabular}{lccc}
\hline Characteristics & Ribeirão Preto $(\mathrm{n}, \%)$ & São Luís $(\mathrm{n}, \%)$ & $\mathrm{P}$ \\
\hline Pre-gestational BMI $\left(\mathrm{kg} / \mathrm{m}^{2}\right)$ & & & $<0.001$ \\
$18.5-24.9$ & $733(52.7 \%)$ & $929(66.3 \%)$ & \\
$<18.5$ & $100(7.2 \%)$ & $110(7.9 \%)$ & \\
$25-29.9$ & $364(26.2 \%)$ & $277(19.7 \%)$ & \\
$\geqslant 30$ & $193(13.9 \%)$ & $86(6.1 \%)$ & \\
Prenatal control $(\geqslant 6$ visits) & $1245(94.8 \%)$ & $1077(82.9 \%)$ & \\
$\quad$ Yes & $69(5.2 \%)$ & $221(17.1 \%)$ & \\
$\quad$ No & & & \\
Gestational diabetes & $73(5.3 \%)$ & $37(2.7 \%)$ & \\
$\quad$ Yes & $1297(94.7 \%)$ & $1344(97.3 \%)$ & \\
$\quad$ No & $192(14.0 \%)$ & $233(16.9 \%)$ & 0.038 \\
Gestational hypertension & $1178(86.0 \%)$ & $1148(83.1 \%)$ & \\
$\quad$ Yes & & & $<0.001$ \\
$\quad$ No & $817(59.6 \%)$ & $689(49.8 \%)$ & \\
Type of delivery & & & \\
$\quad$ Vaginal & & & \\
\hline
\end{tabular}

Chi-squared test was used. BMI: body mass index.

Table 3. Anthropometric and blood pressure profiles of pregnant women in Ribeirão Preto and São Luís 2010 birth cohorts.

\begin{tabular}{|c|c|c|c|c|c|c|c|}
\hline \multirow[t]{2}{*}{ Anthropometric and blood pressure profile } & \multicolumn{3}{|c|}{ Ribeirão Preto } & \multicolumn{3}{|c|}{ São Luís } & \multirow[t]{2}{*}{$\mathrm{P}$} \\
\hline & $\mathrm{n}$ & Mean & SD & $\mathrm{n}$ & Mean & SD & \\
\hline Pre-gestational weight $(\mathrm{kg})$ & 1390 & 63.6 & 14.5 & 1418 & 56.3 & 10.9 & $<0.001$ \\
\hline Height $(m)$ & 1400 & 1.60 & 0.06 & 1429 & 1.56 & 0.05 & $<0.001$ \\
\hline Pre-gestational BMI $\left(\mathrm{kg} / \mathrm{m}^{2}\right)$ & 1390 & 24.5 & 5.2 & 1402 & 23.0 & 4.1 & $<0.001$ \\
\hline Gestational BMI & 1396 & 27.1 & 5.2 & 1419 & 25.5 & 4.1 & $<0.001$ \\
\hline Systolic blood pressure (mmHg) & 1398 & 108.4 & 9.8 & 1413 & 102.8 & 10.1 & $<0.001$ \\
\hline Diastolic blood pressure $(\mathrm{mmHg})$ & 1399 & 65.9 & 7.6 & 1413 & 61.8 & 8.1 & $<0.001$ \\
\hline
\end{tabular}

Student's $t$-test was used. BMI: body mass index.

The means (SD) of the biochemical tests were 220 (40.5) $\mathrm{mg} / \mathrm{dL}$ for total cholesterol, 118.9 (36.1) $\mathrm{mg} / \mathrm{dL}$ for LDL-C, 65.5 (13.6) mg/dL for HDL-C, 176.7 (66.9) $\mathrm{mg} / \mathrm{dL}$ for triglycerides, and $82.4(18.3) \mathrm{mg} / \mathrm{dL}$ for glycemia. When the two populations were compared, all biochemical values were statistically higher in RP, except for triglycerides (Table 4).

When applying the cutoff points for metabolic syndrome (MS) indicators according to Chatzi criteria (18), we observed that altered blood pressure $(4 \%)$, altered glycemia (16.5\%), and obesity (13.6\%) were higher in RP than SL $(2,9.9$, and $5.6 \%$, respectively). Only altered rates of HDL-C were higher in SL pregnant women $(13.9 \%)$, whereas no differences were observed between the cities regarding altered triglycerides (Table 5).

\section{Discussion}

Compared with SL, pre-gestational BMI, blood pressure, and all biochemical tests were significantly higher in RP, except for triglycerides. Similar findings were observed in a previous study for cholesterol, triglycerides, HDL-C, and LDL-C in eutrophic pregnant women between 24- to 29-weeks GA (20). The normal physiology of pregnancy includes insulin resistance, increasing adipose tissue, hyperlipidemia, an increase in blood pressure, and activation of the inflammatory cascade. During pregnancy, approximately $6-8 \%$ of women develop gestational diabetes and 3-5\%, hypertension (21). Pregnancy contributes significantly to weight gain in women; data reveal that $42 \%$ of women gain weight above the Institute of Medicine's (IOM) recommendations during pregnancy, 
Table 4. Biochemical profile of pregnant women in Ribeirão Preto and São Luís 2010 birth cohorts.

\begin{tabular}{|c|c|c|c|c|c|c|c|}
\hline \multirow[t]{2}{*}{ Biochemical profile (mg/dL) } & \multicolumn{3}{|c|}{ Ribeirão Preto } & \multicolumn{3}{|c|}{ São Luís } & \multirow[t]{2}{*}{$\mathrm{P}$} \\
\hline & $\mathrm{n}$ & Mean & SD & $\mathrm{n}$ & Mean & SD & \\
\hline Total Cholesterol & 1393 & 226.3 & 41.4 & 1412 & 213.7 & 38.6 & $<0.001$ \\
\hline LDL Cholesterol & 1393 & 121.3 & 34.7 & 1413 & 116.5 & 37.3 & $<0.001$ \\
\hline HDL Cholesterol & 1393 & 68.1 & 14.1 & 1407 & 62.8 & 12.5 & $<0.001$ \\
\hline Triglycerides & 1393 & 178.6 & 68 & 1413 & 174.8 & 65.8 & 0.135 \\
\hline Glycemia & 1393 & 84.5 & 19.1 & 1413 & 80.2 & 17.2 & $<0.001$ \\
\hline
\end{tabular}

Student's t-test was used. SD: standard deviation; LDL: low density lipoprotein; HDL: high density lipoprotein.

Table 5. Altered metabolic syndrome components in Ribeirão Preto and São Luís 2010 birth cohorts.

\begin{tabular}{lccr}
\hline Altered metabolic syndrome components & Ribeirão Preto $(\mathrm{n}, \%)$ & São Luís $(\mathrm{n}, \%)$ & $\mathrm{P}$ \\
\hline Triglycerides $(\geqslant 150 \mathrm{mg} / \mathrm{dL})$ & $855(61.4 \%)$ & $841(59.5 \%)$ & 0.314 \\
Blood pressure $(\geqslant 130 / \geqslant 85 \mathrm{~mm} \mathrm{Hg})$ & $56(4.0 \%)$ & $29(2.0 \%)$ & 0.002 \\
HDL cholesterol $(<50 \mathrm{mg} / \mathrm{dL})$ & $104(7.5 \%)$ & $196(13.9 \%)$ & $<0.001$ \\
Glycemia $(\geqslant 100 \mathrm{mg} / \mathrm{dL})$ & $230(16.5 \%)$ & $141(9.9 \%)$ & $<0.001$ \\
Obesity $\left(\mathrm{BMI}>30 \mathrm{~kg} / \mathrm{m}^{2}\right)$ & $189(13.6 \%)$ & $79(5.6 \%)$ & $<0.001$ \\
\hline
\end{tabular}

Chi-squared test was used. HDL: high density lipoprotein; BMI: body mass index.

and are more likely to develop MS than those without a history of excessive weight gain (22).

The definitions of metabolic factors (MF) associated with non-transmissible diseases in pregnancy are also controversial because the criteria for detecting those factors overlap with the physiological changes of pregnancy. Women with pre-gestational altered MF are more likely to develop complications during pregnancy, such as pre-eclampsia, eclampsia, gestational diabetes, and coma (23).

The unfavorable metabolic profile of pregnant women in RP can be attributed to the higher consumption of beverages during pregnancy, a four-fold incidence of smoking, more smokers who smoked more than 10 cigarettes per day (heavy smoker), and lower levels of physical activity. On the other hand, the absence of difference in the Block score, which evaluates a high-fat diet, can be attributed to limited sensitivity of the method. It can also be speculated that greater access to food can be associated with a higher socioeconomic level in RP compared to SL.

The development of an unfavorable metabolic profile is highly related to changes in the population's nutritional profile, due to nutritional transition. An unhealthy nutritional transition (increased malnutrition - energy-dense foods) can lead to shortened growth (stunting) and weight gain in children, adolescents, and adults, resulting in higher BMI and worse health outcomes throughout the life cycle (24).
The present study demonstrated that pregnant women in RP presented disturbing levels of overweight and obesity, already in the pre-conception period, in contrast to women in SL, a fact that allows us to speculate whether the nutritional transition seems to be more advanced in the more developed city.

Another explanation for the observed paradoxes of the more developed city (RP) having higher rates of low schooling and lower $\mathrm{C}$-section rates are the convenience sampling.

In an Argentine study, total cholesterol of 159.8 (32.5) $\mathrm{mg} / \mathrm{dL}$, LDL-C of 78.0 (26.3) mg/dL, HDL-C of 57.6 (11.5) $\mathrm{mg} / \mathrm{dL}$, and triglycerides of 89.9 (33.8) $\mathrm{mg} / \mathrm{dL}$ were observed in pregnant women in the first trimester $(n=248)$ (25). In our study, all values were much higher, reflecting the nutritional status of pregnant women at the beginning of pregnancy and their lifestyle; also, all biochemical values were significantly higher in RP, except for triglycerides (Table 3).

The greater rates of gestational diabetes and altered non-fasting glycemia in RP agrees with a previous study (26) on the need to investigate pre-gestational metabolic syndrome. Maternal health in association with nutritional status is the most important factor related to pregnancy outcomes and perinatal morbidity (27).

A limitation of the study was the measure of glycemia without fasting, because it was a study involving pregnant women, in an evaluation that took an average of $4 \mathrm{~h}$, which may have over- or underestimated the results. 
Nonetheless, the main study objective was to compare the two cities regarding the metabolic profile.

The main study strength was the comparison of data from two cohorts with marked socioeconomic and nutritional transition contrasts, which allowed better detection of differences in metabolic markers that pose risks to the mother and her fetus. These risks not only have a longterm impact on maternal health but are also responsible for many abnormalities in children like the risk of metabolic syndrome and cardiovascular disease induction (28).

In conclusion, RP had a worse gestational metabolic profile than SL in pregnant women, with higher pregestational excess weight, indicating a nutritional transition in the more developed city. The components of the metabolic factors associated with non-transmissible diseases must be diagnosed early in order to offer the

\section{References}

1. Kac G, Velásquez-Meléndez $G$. The nutritional transition and the epidemiology of obesity in Latin America. Cad Saude Publica 2003; 19: S5, S4, doi: 10.1590/s0102$311 \times 2003000700001$.

2. Liu LX, Arany Z. Maternal cardiac metabolism in pregnancy. Cardiovasc Res 2014; 101: 545-553, doi: 10.1093/cvr/ cvu009.

3. Rich-Edwards JW, Fraser A, Lawlor DA, Catov JM. Pregnancy characteristics and women's future cardiovascular health: an underused opportunity to improve women's health? Epidemiol Rev 2014; 36: 57-70, doi: 10.1093/ epirev/mxt006.

4. Lawlor DA, Relton C, Sattar N, Nelson SM. Maternal adiposity-a determinant of perinatal and offspring outcomes? Nat Rev Endocrinol 2012; 8: 679-688, doi: 10.1038/nrendo. 2012.176.

5. Lawlor DA. The Society for Social Medicine John Pemberton lecture 2011. developmental overnutrition - an old hypothesis with new importance? Int J Epidemiol 2013; 42: 7-2, doi: $10.1093 / \mathrm{ije} / \mathrm{dys} 209$.

6. Mazurkiewicz JC, Watts GF, Warburton FG, Slavin BM, Lowy C, Koukkou E. Serum lipids, lipoproteins and apolipoproteins in pregnant non-diabetic patients. J Clin Pathol 1994; 47: 728-731, doi: 10.1136/jcp.47.8.728.

7. Saarelainen $H$, Laitinen $T$, Raitakari OT, Juonala $M$, Heiskanen N, Lyyra-Laitinen $T$, et al. Pregnancy-related hyperlipidemia and endothelial function in healthy women. Circ J 2006; 70: 768-772, doi: 10.1253/circj.70.768.

8. El Khouly NI, Sanad ZF, Saleh SA, Shabana AA, Elhalaby $A F$, Badr EE. Value of first-trimester serum lipid profile in early prediction of preeclampsia and its severity: A prospective cohort study. Hypertens Pregnancy 2016; 35: 73-81, doi: 10.3109/10641955.2015.1115060.

9. Göbl CS, Handisurya A, Klein K, Bozkurt L, Luger A, Bancher-Todesca $D$, et al. Changes in serum lipid levels during pregnancy in type 1 and type 2 diabetic subjects. Diabetes Care 2010; 33: 2071-2073, doi: 10.2337/dc10-0484.

10. Ye K, Bo QL, Du QJ, Zhang D, Shen Y, Han YP, et al. Maternal serum lipid levels during late pregnancy and opportunity for health professionals to intervene, with the aim of promoting health and preventing complications, for both the mother and her newborn.

\section{Acknowledgments}

We acknowledge the women who generously contributed with information to the research. This study was supported by Fundação de Amparo à Pesquisa do Estado de São Paulo (FAPESP; Process No. 08/53593-0), Fundação de Apoio ao Ensino, Pesquisa e Assistência do Hospital das Clínicas da Faculdade de Medicina de Ribeirão Preto da Universidade de São Paulo (FAEPA), and Bolsa de Pós-Graduação da Coordenação de Aperfeiçoamento de Pessoal de Nível Superior (CAPES/ PROAP).

neonatal body size. Asia Pac J Clin Nutr 2015; 24: 138143, doi: 10.6133//apjcn.2015.24.1.20.

11. Kaess B, Fischer M, Baessler A, Stark K, Huber F, Kremer W, et al. The lipoprotein subtraction profile: Heritability and identification of quantitative trait loci. $J$ Lipid Res 2008; 49: 715-723, doi: 10.1194/jIr.M700338-JLR200.

12. Wang $Q$, Würtz $P$, Auro $K$, Mäkinen $V P$, Kangas $A J$, Soininen $\mathrm{P}$, et al. Metabolic profiling of pregnancy: Crosssectional and longitudinal evidence. BMC Med 2016; 14: 205, doi: 10.1186/s12916-016-0733-0.

13. da Silva AA, Simões VM, Barbieri M, Cardoso V, Alves CM, Thomaz EBAF, et al. A protocol to identify non-classical risk factors for preterm births: the Brazilian Ribeirão Preto and São Luís prenatal cohort (BRISA). Reprod Health 2014; 11: 79, doi: 10.1186/1742-4755-11-79.

14. ABEP. Associação Brasileira de Empresas de Pesquisa. Critério Padrão de Classificação Econômica Brasil; 2009.

15. Block G, Gillespie C, Rosenbaum EH, Jenson C. A rapid food screener to assess fat and fruit and vegetable intake. Am J Prev Med 2000; 18: 284-288, doi: 10.1016/S07493797(00)00119-7.

16. Craig CL, Marshall AL, Sjöström M, Bauman AE, Booth ML, Ainsworth $\mathrm{BE}$, et al. International physical activity questionnaire: 12-Country reliability and validity. Med Sci Sports Exerc 2003; 35: 1381-1395, doi: 10.1249/01.MSS.00000789 24.61453.FB.

17. World Health Organization. Physical status: the use and interpretation of anthropometry. Report of a WHO Expert Committee. 1995.

18. Chatzi L, Plana E, Daraki V, Karakosta P, Alegkakis D, Tsatsanis $C$, et al. Metabolic syndrome in early pregnancy and risk of preterm birth. Am J Epidemiol 2009; 170: 829836, doi: 10.1093/aje/kwp211.

19. Vandenbroucke JP, von Elm E, Altman DG, Gøtzsche PC, Mulrow CD, Pocock SJ, et al. Strengthening the reporting of observational studies in epidemiology (STROBE): explanation and elaboration. Int $J$ Surg 2014; 12: 1500-1524, doi: 10.1016/j.jjsu.2014.07.014. 
20. Martin CL, Vladutiu CJ, Zikry TM, Grace MR, Siega-Riz AM. Maternal lipid levels during pregnancy and child weight status at three years of age. Pediatr Obes 2019; 14: e12485, doi: 10.1111/ijpo.12485.

21. Paramsothy $P, K$ nopp RH. Metabolic syndrome in women of childbearing age and pregnancy: recognition and management of dyslipidemia. Metab Syndr Relat Disord 2005; 3: 250-258, doi: 10.1089/met.2005.3.250.

22. Cogswell M, Scanlon KS, Fein SB, Schieve LA. Medically advised, mother's personal target, and actual weight gain during pregnancy. Obstet Gynecol 1999; 94: 616-622, doi: 10.1016/S0029-7844(99)00375-0.

23. Bartha JL, González-Bugatto F, Fernández-Macías R, González-González NL, Comino-Delgado R, Hervías-Vivancos B. Metabolic syndrome in normal and complicated pregnancies. Eur J Obstet Gynecol Reprod Biol 2008; 137: 178-184, doi: 10.1016/j.ejogrb.2007.06.011.

24. Güngör NK. Overweight and obesity in children and adolescents. J Clin Res Pediatr Endocrinol 2014; 6: 129_ 143, doi: 10.4274/jcrpe.1471.
25. Ywaskewycz Benítez LR, Bonneau GA, Castillo Rascón MS, López DL, Pedrozo WR. Perfil lipídico por trimestre de gestación en una población de mujeres adultas [in Spanish]. Rev Chil Obstet Ginecol 2010; 75: 227-233, doi: 10.4067/S0717-7526201000040 0003.

26. Noussitou P, Monbaron D, Vial Y, Gaillard RC, Ruiz J. Gestational diabetes mellitus and the risk of metabolic syndrome: a population-based study in Lausanne, Switzerland. Diabetes Metab 2005; 31: 361-369, doi: 10.1016/ S1262-3636(07)70205-7.

27. Koblinsky MA. Beyond maternal mortality - magnitude, interrelationship and consequences of women's health, pregnancy-related complications and nutritional status on pregnancy outcomes. Int J Gynecol Obstet 1995; 48: S21-S32, doi: 10.1016/0020-7292(95)02322-4.

28. Palinski W. Effect of maternal cardiovascular conditions and risk factors on offspring cardiovascular disease. Circulation 2014; 129: 2066-2077, doi: 10.1161/CIRCULATIONAHA. 113.001805 . 